\title{
PENGARUH KARAKTERISTIK KEPEMIMPINAN TERHADAP \\ MOTIVASI KERJA KARYAWAN DI PT. MEGA MEDICA PHARMACEUTICALS
}

\begin{abstract}
ABSTRAK
Cindy Natalia Rianti, Rizki Afri Mulia, Annisa Fitri

Penelitian ini bertujuan untuk : 1) Mengetahui karakteristik kepemimpinan di PT. Mega Medica Pharmaceuticals. 2) Mengetahui motivasi kerja karyawan di PT. Mega Medica Pharmaceuticals. 3) Mengetahui seberapa besar pengaruh karakterisrik kepemimpinan terhadap motivasi kerja karyawan di PT. Mega Medica Pharmaceuticals.

Metode penelitian yang digunakan dalam penelitian ini adalah penelitian kuantitatif korelasional yaitu penelitian yang bertujuan untuk mengetahui hubungan dua variabel atau lebih dan dapat saling mempengaruhi. Pada penelitian ini, pemilihan sampel yang dilakukan dalam penelitian ini menggunakan teknik proportional random sampling.

Hasil penelitan ini adalah : 1) Secara khusus disimpulkan bahwa karakteristik kepemimpinan karyawan PT. Mega Medica Pharmaceuticals sudah dapat dikategorikan baik dengan nilai rata-rata 4.07. 2) Dari data yag telah dikumpulkan untuk motivasi kerja karyawan di PT. Mega Medica Pharmaceuticals yaitu aktualisasi diri dengan jumlah nilai rata-rata 4.29, diikuti dengan harga diri dengan nilai 4.16, diikuti dengan kebersamaan, social dan cinta dengan nilai 4.03, diikuti dengan keamanan dan keselamatan dengan nilai 3.59,yang paling rendah adalah fisiologis dengan nilai 3.82.3) Dari hasil penelitian didapatkan bahwa pengaruh karakteristik kepemimpinan terhadap motivasi kerja karyawan di PT. Mega Medica Pharmaceuticals sebesar $27.35 \%$. Sisanya $72.65 \%$ dipengaruhi oleh faktorfaktor lain yang tidak diteliti dalam penelitian ini.
\end{abstract}

Kata Kunci : Karakteristik Kepemimpinan, Motivasi, Karyawan 


\section{EFFECT OF LEADERSHIP CHARACTERISTICS OF EMPLOYEE MOTIVATION IN PT. MEGA MEDICA PHARMACEUTICALS}

\section{ABSTRACT}

\section{Cindy Natalia Rianti, Rizki Afri Mulia}

This study aims to: 1) Determine the characteristics of leadership in PT. Mega Medica Pharmaceuticals. 2) Knowing the work motivation of employees at PT. Mega Medica Pharmaceuticals. 3) Knowing how much influence the characteristics of leadership on employee motivation at PT. Mega Medica Pharmaceuticals.

The research method used in this research is correlational quantitative research that is research that aims to determine the relationship of two or more variables and can influence each other. In this study, sample selection is carried out in this study using a proportional random sampling technique.

The results of this research are: 1) Specifically concluded that the leadership characteristics of the employees of PT. Mega Medica Pharmaceuticals can already be categorized well with an average value of 4.07. 2) From the data that has been collected for work motivation of employees at PT. Mega Medica Pharmaceuticals is self-actualization with an average value of 4.29 , followed by self-esteem with a value of 4.16 , followed by togetherness, social and love with a value of 4.03 , followed by security and safety with a value of 3.59, the lowest is physiological with a value of 3.82 . 3) From the results of the study found that the influence of leadership characteristics on employee work motivation at PT. Mega Medica Pharmaceuticals by $27.35 \%$. The remaining $72.65 \%$ is influenced by other factors not examined in this study.

Keywords: Leadership Characteristics, Motivation, Employees 


\section{PENDAHULUAN}

Organisasi pasti menginginkan para pegawainya memiliki kinerja yang baik agar proses pencapaian tujuan berjalan dengan lancar. Dalam mewujudkan kinerja pegawai yang diinginkan, terdapat banyak faktor yang mempengaruhi pegawai antara lain kepemimpinan pada organisasi tersebut, budaya organisasi, kompensasi, motivasi, iklim kerja dan lain sebagainya. Berkaitan dengan hal tersebut, dalam penelitian ini akan membahas dua faktor yang diidentifikasi mempengaruhi motivasi kerja yaitu kepemimpinan.

Faktor pertama yang diidentifikasi mempengaruhi motivasi kerja pegawai adalah kepemimpinan. Kepemimpinan merupakan kemampuan untuk mempengaruhi kelompok menuju pencapaian tujuan yang telah ditentukan. Kepemimpinan berpengaruh kuat terhadap kemajuan organisasi. Kualitas pemimpin sering dianggap sebagai faktor terpenting yang menentukan keberhasilan suatu organisasi. Pemimpin yang efektif sanggup mempengaruhi para pengikutnya untuk mempunyai optimisme yang lebih besar, percaya diri, serta komitmen pada tujuan organisasi yang telah ditentukan. Hal ini membawa konsekuensi bahwa setiap pemimpin berkewajiban untuk memberikan perhatian sungguh-sungguh dalam membina, menggerakkan, dan mengarahkan seluruh potensi pegawai di lingkungannya agar dapat mewujudkan stabilitas organisasi dan peningkatan kinerja pegawai yang berorientasi pada tujuan organisasi.

Keberhasilan atau kegagalan suatu organisasi atau perusahaan ditentukan oleh kemampuan dan keluwesan kepemimpinan dalam mengelola sumber daya yang ada pada organisasi. Karyawan akan bekerja secara optimal apabila melalui pekerjaan yang dilakukannya bisa memenuhi kebutuhan hidupnya, artinya perusahaan benar-benar harus bisa memperhatikan tingkat kebutuhan karyawannya.

Salah satu perusahaan yang akan diteliti oleh penulis adalah PT. Mega Medica Pharmaceuticals. Kebijakan-kebijakan yang ada mampu mempengaruhi motivasi terhadap karyawan-karyawan perusahaan karena keharmonisan hubungan kerja dapat tercipta apabila karyawan mau dan merasa senang bekerja di bawah pimpinan yang bisa memberikan motivasi atau dorongan yang baik kepada mereka. Dengan bisa memberikan dan memenuhi kebutuhan karyawan tersebut maka dapat menjadi suatu pendorong motivasi kerja karyawan agar bisa bekerja lebih baik. Melihat betapa pentingnya peran seorang pemimpin seperti yang diuraikan diatas, maka pemimpin harus bisa menciptakan bawahannya agar lebih produktif dan tujuan perusahaan tercapai secara efektif dan efisien.(Mulia, 2019)

Berdasarkan pengamatan dan observasi prapenelitian, masih ada beberapa karyawan PT. Mega Medica Pharmaceuticals yang memiliki motivasi kerja yang rendah. Faktor yang mempengaruhi motivasi kerja 
karyawan selain rendahnya keterampilan dan kemampuan dalam menyelesaikan tugas yaitu pengawasan dan motivasi dari pimpinan. Pengawasan oleh pimpinan sangatlah penting sebagai proses untuk menjamin bahwa karyawan menjalankan tugas sesuai tujuan organisasi dan standar kinerja yang sudah ditentukan. Pimpinan PT. Mega Medica Pharmaceuticals belum rutin melakukan pengawasan ke tiap bidang. Sehingga, berdampak pada rendahnya pengetahuan pimpinan terkait masalah motivasi kerja karyawan di PT. Mega Medica Pharmaceuticals. Rendahnya pengawasan pimpinan PT. Mega Medica Pharmaceuticals terhadap karyawan berdampak pada semangat kerja dan kinerja karyawan PT. Mega Medica Pharmaceuticals. Tujuan penelitian berdasarkan rumusan masalah diatas yaitu untuk mengetahui karakteristik kepemimpinan di PT. Mega Medica Pharmaceuticals. Mengetahui motivasi kerja karyawan di PT. Mega Medica Pharmaceuticals. Mengetahui seberapa besar pengaruh karakterisrik kepemimpinan terhadap motivasi kerja karyawan di PT. Mega Medica Pharmaceuticals.

\section{METODE PENELITIAN}

Metode penelitian yang digunakan dalam penelitian ini adalah penelitian kuantitatif korelasional yaitu penelitian yang bertujuan untuk mengetahui hubungan dua variabel atau lebih dan dapat saling mempengaruhi. Adapun unit analisis dalam penelitian ini adalah karyawan yang terdapat di PT. Mega Medica Pharmaceuticals.

Nawawi (1995) mendefinisikan bahwa Populasi adalah totalitas semua nilai yang mungkin, baik hasil menghitung dengan pengukuran kuantitatif maupun kualitatif pada karakteristik tertentu mengenai sekumpulan objek yang lengkap. Sedangkan Arikunto (2002)menyatakan populasi sebagai keseluruhan subjek penelitian. Dalam penelitian ini yang menjadi populasi adalah keseluruhan dari karyawan yang terdapat di PT. Mega Medica Pharmaceuticals. Sampel merupakan bagian dari populasi atau yang mewakili populasi sekaligus menggambarkan populasi itu sendiri. Arikunto (2002:109) menyatakan bahwa sampel adalah sebagian atau wakil dari populasi yang diteliti. Sampel juga merupakan suatu pendugaan terhadap populasi dan bukan populasi itu sendiri (Bambang Prasetyo dan Miftahul Jannah, 2005 : 119). Dengan demikain dapat disimpulkan bahwa sampel adalah sebagian (besar atau kecil) dari keseluruhan populasi yang mewakili populasi secara keseluruhan, dilibatkan langsung dalam proses penelitian. Adapun penelitian dilakukan terhadap karyawan PT. Mega Medica Pharmaceuticals pada bulan Maret - Agustus 2018. Lokasi yang dipilih sebagai tempat penelitian untuk keperluan penelitian proyek akhir ini adalah PT. Mega Medica Pharmaceuticals bertempat di Ruko Megah, Kalideres.

\section{HASIL DAN PEMBAHASAN}




\section{Pembahasan Hasil Kuesioner Karakteristik Kepemimpinan Terhadap Motivasi Kerja Karyawan.}

Tabel 1. Hasil Korelasi Antara Karakteristik Kepemimpinan dengan Motivasi Kerja Karyawan

\section{Correlations}

\begin{tabular}{|ll|r|r|}
\hline & & $\begin{array}{c}\text { Karakteristik } \\
\text { Kepemimpina } \\
\mathrm{n}\end{array}$ & \multicolumn{1}{c|}{$\begin{array}{c}\text { Motivasi } \\
\text { Kerja } \\
\text { Karyawan }\end{array}$} \\
\hline Karakteristik & Pearson & 1 & $.523^{* *}$ \\
Kepemimpinan & Correlation & & .000 \\
& Sig. (2-tailed) & 72 & 72 \\
Motivasi Kerja & Pearson & $.523^{* *}$ & 1 \\
Karyawan & Correlation & & 72 \\
& Sig. (2-tailed) & .000 & \\
& $\mathrm{~N}$ & 72 & \\
\hline
\end{tabular}

Dalam tabel diatas dapat dilihat bahwa hubungan antara karakteristik kepemimpinan dengan motivasi kerja karyawan adalah 0.523 dengan asumsi bahwa karakteristik kepemimpinan mempunyai hubungan yang cukup baik. Hal ini menunjukkan bahwa karakteristik kepemimpinan dengan motivasi kerja karyawan signifikan berarti motivasi kerja karyawan di PT. Mega Medica Pharmaceuticals sudah cukup baik.

Untuk megetahui berapa besar pengaruh karakteristik kepemimpinan terhadap motivasi karyawan PT. Mega Medica Pharmaceutical, dihitung koefisien determinasi dengan rumus $\mathrm{KD}=\mathrm{R}^{2} \mathrm{x} 100 \%$. Didapatkan hasil sebagai berikut:

$$
\begin{aligned}
& \mathrm{KD}=0.523^{2} \times 100 \% \\
& \mathrm{KD}=0.273529 \times 100 \% \\
& \mathrm{KD}=\mathbf{2 7 . 3 5 \%}
\end{aligned}
$$


Hasil perhitungan tersebuut menunjukkan pengaruh karakteristik kepemimpinan terhadap motivasi kerja karyawan di PT. Mega Medica Pharmaceuticals sebesar $27.35 \%$. Sisanya $72.65 \%$ dipengaruhi oleh faktorfaktor lain yang tidak diteliti dalam penelitian ini.

\section{Analisis Regresi Linear Sederhana.}

Tabel 2

\begin{tabular}{|l|l|c|l|}
\hline \multicolumn{4}{|c|}{ Variables Entered/Removed $^{\mathrm{a}}$} \\
\hline Model & \multicolumn{1}{|c|}{$\begin{array}{c}\text { Variables } \\
\text { Entered }\end{array}$} & $\begin{array}{c}\text { Variables } \\
\text { Removed }\end{array}$ & Method \\
\hline 1 & $\begin{array}{l}\text { Karakteristik } \\
\text { Kepemimpinan }\end{array}$ & & Enter \\
& & & \\
\hline
\end{tabular}

a. Dependent Variable: Motivasi Kerja Karyawan

b. All requested variables entered.

Tabel diatas menjelasan tentang Karateristik Kepemimpinan sebagai variabel Independent dan Motivasi kerja karyawan sebagai variabel Dependent dengan metode Enter.

Tabel 3

\begin{tabular}{|c|c|c|c|c|}
\hline \multicolumn{5}{|c|}{ Model Summary } \\
\hline Model & $\mathrm{R}$ & R Square & $\begin{array}{c}\text { Adjusted R } \\
\text { Square }\end{array}$ & $\begin{array}{l}\text { Std. Error of } \\
\text { the Estimate }\end{array}$ \\
\hline 1 & $.523^{\mathrm{a}}$ & .274 & .264 & 3.95242 \\
\hline
\end{tabular}

a. Predictors: (Constant), Karakteristik Kepemimpinan

Tabel 4.52 menjelaskan nilai korelasi/ hubungan ${ }^{\circledR}$ yaitu sebesar 0.523. Dari tabel tersebut diperoleh koefisien seterminasi (R Square) sebesar 0.274 , yang mengandung pengertian bahwa variabel $\mathrm{X}$ (Karakteristik Kepemimpinan) terhadap variabel Y (Motivasi Kerja Karyawan) adalah sebesar $27.4 \%$.

Tabel 4. Coefficients ${ }^{\mathrm{a}}$

\begin{tabular}{|l|c|c|c|c|}
\hline Model & $\begin{array}{c}\text { Unstandardized } \\
\text { Coefficients }\end{array}$ & $\begin{array}{c}\text { Standardized } \\
\text { Coefficients }\end{array}$ & $\mathrm{t}$ & Sig. \\
\hline
\end{tabular}




\begin{tabular}{|l|l|r|r|r|r|r|}
\hline \multicolumn{2}{|c|}{} & \multicolumn{1}{|c|}{ B } & Std. Error & Beta & & \\
\hline 1 & Constant $)$ & 35.126 & 4.798 & & 7.320 & .000 \\
\hline \multicolumn{1}{|l|}{$\begin{array}{l}\text { Karakteristik } \\
\text { Kepemimpinan }\end{array}$} & .416 & .081 & .523 & 5.139 & .000 \\
\hline
\end{tabular}

a. Dependent Variable: Motivasi Kerja Karyawan

Tabel 5 diketahui Constant (a) sebesar 35.126, sedangkan nilai dari karakteristik kepemimpinan (b / koefisien regresi) sebesar 0.416 sehingga persamaan regresinya dapat ditulis:

$\mathrm{Y}=\mathrm{a}+\mathrm{bX}$

$Y=35.126+0.416 X$

Persamaan tersebut dapat dijelaskan bahwa variabel karakteristik kepemimpinan adalah sebasar 35.126 dan koefisien regresi sebesar 0.416 menyatakan bahwa setiap penambahan $1 \%$ nilai Karakteristik kepemimpinan, maka nilai Motivasi kerja karyawan bertambah sebesar 0.416 . Koefisien regresi bernilai positif, sehingga dapat dikatakan bahwa arah pengaruh $\mathrm{X}$ terhadap $\mathrm{Y}$ adalah positif.

Berdasarkan nilai sigifikasi dari tabel 4.53 diperoleh nilai signifikasi $0.000<0.005$ sehingga dapat disimpulkan bahwa variabel Karakteristik Kepemimpinan berpengaruh terhadap variabel Motivasi kerja karyawan.

Menghitung nilai tabel

$$
\begin{aligned}
\mathrm{T}_{\text {tabel }} & =(\mathrm{a} / 2: \mathrm{n}-\mathrm{k}-1) \\
& =(0.05 / 2: 72-1-1) \\
& =(0.025: 70) \\
& =3.571
\end{aligned}
$$

Berdasarkan nilai t diketahui thitung sebesar 5.139 > tabel 3.571, sehingga dapat disimpulkan bahwa variabel Karakteristik Kepemimpinan Motivasi Kerja Karyawan. Motivasi Kerja Karyawan. 


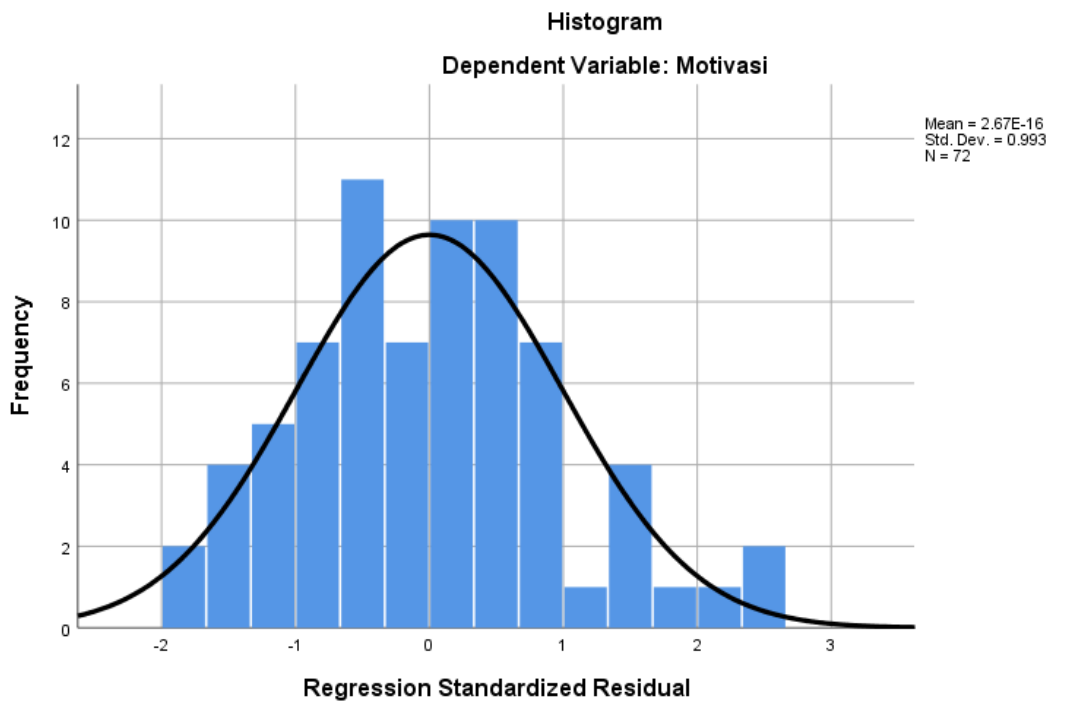

\section{Kesimpulan}

Dari hasil data yang dikumpulkan, dianalisis, dan dihitung oleh penulis dengan menggunakan bantuan program SPSS versi 21 mengenai pengaruh pengaruh karakteristik kepemimpinan terhadap motivasi karyawan PT. Mega Medica Pharmaceuticals dapat disimpulkan bahwa:

1. Secara khusus disimpulkan bahwa karakteristik kepemimpinan karyawan PT. Mega Medica Pharmaceuticals sudah dapat dikategorikan baik dengan nilai rata-rata 4.07. Karakteristik Kepemimpinan mempunyai nilai tertinggi adalah cara berkomunikasi yaitu dengan nilai 4.21, diikuti dengan Pengambilan keputusan dengan nilai 4.09, diikuti dengan pemberian motivasi dan kekuasaan yang positif dengan nilai 4.05 , dan yang paling rendah adalah pengambilan keputusan dengan nilai 3.95.

2. Dari data yag telah dikumpulkan untuk motivasi kerja karyawan di PT. Mega Medica Pharmaceuticals yaitu aktualisasi diri dengan jumlah nilai rata-rata 4.29 , diikuti dengan harga diri dengan nilai 4.16, diikuti dengan kebersamaan, social dan cinta dengan nilai 4.03, diikuti dengan keamanan dan keselamatan dengan nilai 3.59,yang paling rendah adalah fisiologis dengan nilai 3.82 .

3. Dari hasil penelitian didapatkan bahwa pengaruh karakteristik kepemimpinan terhadap motivasi kerja karyawan di PT. Mega Medica Pharmaceuticals sebesar $27.35 \%$. Sisanya $72.65 \%$ dipengaruhi oleh faktor-faktor lain yang tidak diteliti dalam penelitian ini. 


\section{Saran}

1. Dari hasil yang didapat, karakteristik kepemimpinan sudah sangat baik dari cara berkomunikasinya, dikarenakan komunikasi adalah hal utama yang harus dipakai pada saat bekerja di lapangan. Unutk motivasi kurang baik dikarenakan aktualisasi diri sama seperti mementingkan diri sendiri. Harusnya kebersamaan, social dan cinta yang ditingkatkan antara bawahan dan atasan agar tecapainya prestasi yang bagus untuk perusahaan.

2. Berdasarkan hasil penelitian dan pengaruh keterbatasan yang ada, maka penulis ingin memberikan saran yang mungkin dapat diterapkan dalam penelitian yang akan dating agar diperoleh hasil penelitian yang lebih akurat, yaitu untuk penelitian selanjutnya diharapkan memperluas variabel penelitian seperti ditambah variabel budaya, organisasi, dan komitmen organisasi. Dan juga memperluas sampel dan objek penelitian agar mendapatkan hasil yang akurat. 


\section{DAFTAR PUSTAKA}

Arikunto, S. (2002). Dasar-dasar evaluasi pendidikan / Suharsimi Arikunto (Ed Revisi). Jakarta: Bumi Aksara.

Mulia, R. A. (2019). INFLUENCE OF PUBLIC POLICY, PARTICIPATION OF COMMUNITY AND EDUCATION LEVEL TO PUBLIC WELFARE IN PADANG PARIAMAN DISTRICT. Jurnal EL-RIYASAH, 10(1), 37-56.

Nawawi, H. (1995). Instrumen penelitian bidang sosial. (H. M. M. Hadari, Ed.) (Cet. 2). Yogyakarta: Gadjah Mada University. 